\title{
INTERNET DAS COISAS (IOT) E DIREITO: UMA AVALIAÇÃO DO PLANO DE AÇÃO PARA O BRASIL 2017/2022 SOB A VISÃO SISTÊMICA
}

\author{
Isabela Cristina Sabo* \\ Aires José Rover**
}

Resumo: Empregando-se o método indutivo, o artigo apura se o enfoque jurídico do Plano de Ação em IoT para o Brasil 2017/2022, conduzido pelos órgãos governamentais, segue a ótica sistêmica. Para isso, parte-se de dois objetivos: o teórico, elaborando uma revisão bibliográfica que apresenta a visão sistêmica em Humberto R. Maturana e Francisco J. Varela e as aplicações de IoT em seus diversos segmentos (urbano, rural, industrial, doméstico etc.); e o empírico, realizando uma avaliação qualitativa dos relatórios jurídicos que compõem o Plano de Ação, discutindo os resultados e apontando matérias que possam servir de análises jurídicas futuras.

Palavras-chave: Internet das Coisas; Direito; autopoiese; visão sistêmica, Brasil.

\section{INTERNET OF THINGS (IOT) AND LAW: AN EVALUATION OF THE ACTION PLAN FOR BRAZIL 2017/2022 UNDER SYSTEMIC VIEW}

\begin{abstract}
Employing the inductive method, the article examines if the legal approach of the IoT Action Plan for Brazil 2017/2022, conducted by government agencies, follows the systemic view. To this end, it is based on two objectives: the theoretical, elaborating a bibliographic review that presents the systemic view in Humberto R. Maturana and Francisco J. Varela and the applications of IoT in its different segments (urban, rural, industrial, domestic etc.); and the empirical, doing a qualitative evaluation of the legal reports that compose the Action Plan, discussing the results and pointing matters that may serve as future legal analyzes.
\end{abstract}

Keywords: Internet of Things; Law; autopoiesis; systemic view; Brazil.

\footnotetext{
" Doutoranda em Direito pela Universidade Federal de Santa Catarina. Bolsista do Conselho Nacional de Desenvolvimento Científico e Tecnológico (CNPq). Mestra em Direito Negocial pela Universidade Estadual de Londrina. Graduada em Direito pela Universidade Estadual de Maringá. Membro do Grupo de Pesquisa do CNPq "Governo Eletrônico, Inclusão Digital e Sociedade do Conhecimento".

** Doutor, Mestre e Graduado em Direito pela Universidade Federal de Santa Catarina. Professor Ajunto II da Universidade Federal de Santa Catarina. Líder do Grupo de Pesquisa do CNPq "Governo Eletrônico, Inclusão Digital e Sociedade do Conhecimento".
} 


\section{INTRODUÇÃO}

A Internet das Coisas ("Internet of Things" - IoT) é um promissor segmento da Internet que está gerando inquietações em vários setores. No Brasil, estudos para viabilizar as suas aplicações foram conduzidos pelo Ministério da Ciência, Tecnologia, Inovações e Comunicações (MCTIC) e pelo Banco Nacional de Desenvolvimento Econômico e Social (BNDES), resultando no Plano de Ação em IoT para o Brasil 2017/2022. O tema desafia diversas áreas do conhecimento, como ocorre com o Direito, tendo em vista o aparato de questões jurídicas que surgem a partir de sua implementação e disponibilização à sociedade.

Dadas essas linhas introdutórias, a pesquisa irá apurar se o enfoque jurídico do Plano de Ação em IoT para o Brasil 2017/2022 segue a ótica sistêmica. Para isso, o artigo parte de dois objetivos:

1. No campo teórico, elaborar uma revisão bibliográfica apresentando a visão sistêmica a partir do referencial teórico de Humberto R. Maturana e Francisco J. Varela e as aplicações de IoT em seus diversos segmentos (urbano, rural, industrial, doméstico etc.) (seção 2).

2. No campo empírico, realizar uma avaliação qualitativa dos relatórios jurídicos que compõem o Plano de Ação em IoT para o Brasil 2017/2022, discutir os resultados e apontar matérias que possam servir de análises jurídicas futuras, inclusive como objeto de normas (seção 3). A metodologia empregada será explicada na seção 3.1.

Justifica-se a pesquisa pela atualidade do tema, como também pela ausência de pesquisas jurídicas publicadas e de normas específicas direcionem a atuação do Direito quando da ocorrência de conflitos envolvendo aplicações de IoT. Desse modo, o artigo poderá auxiliar os operadores do Direito e demais interessados da área, no sentido de que os benefícios da tecnologia sejam devidamente explorados e que os resultados sejam alcançados por toda a sociedade.

\section{CONTEXTO E REVISÃO BIBLIOGRÁFICA (ESTADO DA ARTE)}

\subsection{A visão sistêmica a partir de Humberto R. Maturana e Francisco J. Varela}

O aporte teórico de Humberto R. Maturana e Francisco J. Varela constitui uma concepção original no que diz respeito à constituição do ser vivo, sua compreensão e sua 
interação com o meio social sob uma visão sistêmica, tendo como base noções de biologia celular.

O próprio fato de se questionar como se reconhece um ser vivo já indica a formação de uma ideia, mesmo que implícita, do que é a sua organização. "Organização" de algo consiste nas relações que têm de existir, ou têm de ocorrer, para que esse algo, simplesmente, seja. Toma-se como exemplo a cadeira que, para que possa ser assim julgada, deve-se reconhecer certas relações que acontecem entre seus pés, seu espaldar e seu assento, de modo que seja possível sentar nela. $\mathrm{O}$ fato de ser feita de madeira, com pregos, ou de plástico e parafusos é irrelevante para que a qualifique ou a classifique como cadeira. Todavia, poderá ser complexo descrever com exatidão as relações que constituem tal organização (MATURANA; VARELA, 2010, p. 49-50).

"Estrutura", por sua vez, é compreendida como os componentes e as relações que constituem concretamente uma unidade particular e configuram sua organização. A título de exemplo, numa descarga de banheiro, a organização do sistema de regulação do nível da água consiste nas relações entre um aparelho capaz de detectá-lo e outro mecanismo capaz de cortar o fluxo de entrada do líquido. No banheiro de uma casa essa espécie de artefato se configura por meio de um sistema misto de plástico e metal, que consiste numa boia e numa válvula de passagem. Essa estrutura específica poderia ser modificada, substituindo-se o plástico por madeira, sem alterar o fato de que ela continuaria sendo uma descarga (MATURANA; VARELA, 2010, p. 55).

Analisados os conceitos de "organização" e "estrutura", depreende-se que os seres vivos correspondem a unidades particulares e são caracterizados por sua organização autopoiética, que é comum a todos, porém diferem-se entre si por possuírem estruturas distintas. A “autopoiese", por sua vez, é o movimento que caracteriza a autonomia de um dado sistema, o que significa dizer que ele é capaz de especificar sua própria legalidade, aquilo que lhe é próprio. Os seres vivos não são, porém, os únicos sistemas autônomos. O peculiar deles, apenas, é que seu único produto são eles mesmos, inexistindo separação entre produtor e produto (MATURANA; VARELA, 2010, p. 56-57).

Ao distinguir a unidade do ser vivo de seu pano de fundo, tem-se em mãos duas estruturas - a do ser vivo e a do meio - entre as quais ocorre uma congruência estrutural necessária, pois, do contrário, a unidade desaparece. Nessa congruência estrutural, o ser vivo, a partir de sua estrutura, é quem determina quais as mudanças que ocorrerão em resposta às "perturbações" do meio. As mudanças e, por sua vez, os efeitos que resultam da interação entre 
o ser vivo e o meio são desencadeadas pelo agente perturbador e determinadas pela estrutura do sistema perturbado. Em outros termos, o meio apenas desencadeia no ser vivo mudanças determinadas por sua própria estrutura, e não por um agente externo. Essas perturbações poderão resultar em mudanças de estado, como também em mudanças destrutivas do ser vivo (MATURANA; VARELA, 2010, p. 107-108, 110).

Outra compreensão importante é que, nos sistemas vivos, a mudança estrutural se dá tanto como resultado de sua dinâmica interna, como desencadeada por suas interações em um meio que também está em contínua mudança, ou seja, que também corresponde a uma organização autopoiética. E, cada vez que os membros de um conjunto de seres vivos constituem, com sua conduta, uma rede de interações com o meio em que operam, e no qual eles conservam sua organização e adaptação, estar-se-á diante de um sistema social (MATURANA; MAGRO; GRACIANO; VAZ, 1997, p. 196-199). Essa dinâmica também é observada em sistemas artificiais, como é o caso da tecnologia.

A tecnologia, por sua vez, é uma operação em conformidade com as coerências estruturais de diferentes domínios de ações nas quais uma pessoa pode participar como ser humano. Enquanto tal, a tecnologia pode ser vivida como um instrumento para ação intencional efetiva, ou como um valor que justifica ou orienta o modo de viver no qual tudo é subordinado ao prazer vivido ao se lidar com ela. Quando é vivida desse último modo, a tecnologia se torna um vício cuja presença os nela viciados desejam justificar com argumentos racionais fundados na realidade histórica de sua imensa expansão nos tempos modernos. Se vivida como um instrumento para ação efetiva, a tecnologia leva à expansão progressiva de nossas habilidades operacionais em todos os domínios nos quais há conhecimento e compreensão de suas coerências estruturais (MATURANA; MAGRO; PAREDES, 2001, p. 186-187).

Um sistema autopoiético pode chegar a ser componente de outro sistema se algum aspecto de sua trajetória de trocas autopoiéticas pode participar na realização desse outro sistema. Isso pode ocorrer através da evolução, mediante o efeito recorrente de uma pressão seletiva constante sobre o processo de transformação de uma rede histórica e reprodutiva, o que dá por resultado uma subordinação das autopoieses individuais componentes (por meio de troca histórica na modalidade destas) ao ambiente de perturbações mútuas especificado por ela (MATURANA; VARELA, 1997, p. 106).

Analisar o tema sob uma visão sistêmica significa, portanto, observar e interpretar o Direito, a sociedade e as tecnologias como sistemas autopoiéticos, uma vez que detentores de autonomia quanto à sua organização. Suas estruturas são modificáveis a partir do instante em 
que interagem entre si. A interação entre a Internet e o meio permitem tornar "coisas conectadas", e esse sistema, em algum instante, necessitarão interagir com outro sistema, o Direito que, por sua vez, é composto por outros subsistemas conforme suas áreas de atuação e de acordo com os níveis de perturbações que lhe atingem.

\subsection{IoT e suas aplicações}

A IoT consiste em fazer com que as coisas físicas se tornem computadores conectados à Internet. Não quer dizer transformá-las em computadores pessoais, mas sim caracterizá-las como minúsculos computadores, denominados de "coisas inteligentes", em razão de seu agir mais dinâmico comparado às coisas não conectadas. A ideia da IoT não é nova, porém tornouse relevante para o mundo experimental nos últimos tempos devido ao seu progresso no desenvolvimento de hardwares. Assim, a redução de tamanho, dos custos e do consumo de energia, a melhora do desempenho e o impulso à inovação são pontos positivos do assunto (FLEISCH, 2010, p. 3).

Alguns exemplos de aplicações de IoT em meios diversos (ambiental, urbanístico, rural e doméstico etc.) são:

1. A "Smart Palm" (online), instalada em Dubai, é uma estação de recarga de dispositivos autossustentável verde e ponto de informações com acesso Wi-Fi de cortesia. Em outras palavras, consistem em árvores artificiais que utilizam energia solar e fornecem ao público acesso à Internet via Wi-Fi.

2. O "Hikob" (online), desenvolvido na França, é um sistema projetado para coletar, em tempo real, dados brutos ou informações pré-processadas necessárias para áreas de estacionamento e gerenciamento de estacionamento na rua, necessários para a gestão e controle do tráfego urbano e essenciais para tomar decisões. Esse sistema de detecção de veículos e de observação de tempo são constituídos por sensores de magnetômetros sem fios, miniaturizados e de baixa potência e sensores de temperatura e umidade combinados com uma infraestrutura local sem fios que realiza a recolha de dados e conectividade com redes IP ou de telecomunicações ou um equipamento no local.

3. A plataforma "Vehicle to Infrastructure" - "V2I", desenvolvida pela Audi, nos Estados Unidos, assim como o exemplo anterior, é um sistema de informação de semáforos que se comunica com os sinais de trânsito municipais para informar o condutor quando os semáforos passam de vermelho para verde. A tecnologia "V2I" permite que o carro receba informações 
do semáforo em tempo real do sistema avançado de gestão de tráfego que monitora os semáforos (AUDI USA, 2016, online).

4. O "Bigbelly" (online), desenvolvido também nos Estados Unidos, é um reservatório de lixo baseado em energia solar que alertam equipes de saneamento quando estão completos. O sistema objetiva transformar uma das menos eficientes indústrias do planeta, qual seja, a coleta de lixo. Isso porque a coleta de lixo é realizada, muitas vezes, com o desperdício de combustível e de trabalho, e, ainda, com da emissão de $\mathrm{CO}_{2}$. Além disso, latas de lixo transbordando geram uma série de problemas de saúde e segurança. A empresa desenvolvedora tem se esforçado para oferecer uma solução única para o espaço público, alavancando energia solar renovável e tecnologia da informação.

5. O "WaterBee" (online), desenvolvido na Espanha, é um sistema de irrigação e gestão de água inteligente, rentável e completo, que permite otimizar as operações ambientais comerciais e sustentáveis. O sistema de modelagem e agendamento de irrigação inteligente vai além do estado da arte, propiciando não apenas otimizar o uso da água irrigando apenas onde e quando é necessário, mas também aumentando o crescimento e a qualidade da planta.

6. O “Z-Trap" (SPENSA, online), desenvolvido nos Estados Unidos, é um produto destinado a agricultores que dispõe de armadilhas de insetos inteligentes para analisar e prever populações em seus campos. É possível constatar problemas precocemente e usar pesticidas com mais precisão, prevenindo danos às produções e aumentando seus rendimentos. $\mathrm{O}$ sistema permite monitorar as populações de pragas através de um computador ou smartphone.

7. O "MetroBus" (METRO, online), desenvolvido em St. Louis, Missouri, nos Estados Unidos, é um serviço de ônibus público que usa sensores eletrônicos em seus ônibus para coletar dados sobre variáveis como velocidade, temperatura do motor e pressão de óleo. Os computadores analisam os dados e oferecem recomendações aos técnicos de serviço, ajudando a melhorar a confiabilidade do sistema de trânsito da cidade e reduzindo os custos operacionais gerais. O resultado é de menos avarias nos ônibus e tempos de vida do veículo mais longos. Essa identificação de possíveis falhas de manutenção antes que elas aconteçam já fez com que o governo local economizasse cinco milhões de dólares por ano em custos de manutenção e o mesmo valor em custos relacionados a pessoal ${ }^{1}$.

\footnotetext{
${ }^{1}$ Semelhante a esse sistema, na UNICAMP pesquisadores desenvolveram um instrumento que mede a aceleração do veículo e capta a posição geográfica e temporal dos eventos produzidos pelo modo de dirigir do motorista ou pela presença de estruturas e defeitos nas vias, como lombadas e buracos. Toda vez que o ônibus retorna à estação inicial ou terminal, as informações acumuladas são transmitidas automaticamente para um computador central utilizando um dispositivo de comunicação sem fio, via rádio. O instrumento monitora a qualidade do transporte
} 
8. O “Advanced National Seismic System”, do Serviço Geológico dos Estados Unidos (The U.S. Geological Survey), é um sistema que, por meio de acelerômetros e análise de dados em tempo real, monitora a saúde estrutural dos edifícios em regiões sujeitas a terremotos. Os sensores detectam o grau de movimento do edifício, a velocidade com que as ondas sísmicas o percorrem e como a estrutura do edifício muda. Alguns hospitais já implementaram esse sistema para que, em caso de terremoto, seja possível evacuar pacientes e funcionários a tempo (CASTRO; MISRA, 2013, p. 14, 18).

9. A "bengala inteligente", desenvolvida no Brasil por pesquisadores da UTFPR (Universidade Tecnológica Federal do Paraná), em Campo Mourão, é um projeto visa auxiliar pessoas com dificuldades visuais, totais ou parciais, proporcionando autonomia ao deficiente, especificamente para que ele não necessite do auxílio de outras pessoas e possa caminhar sozinho pelo piso podotátil. Atualmente a existência do piso podotátil contribui com esta população, porém este artefato apenas indica caminhos, não sendo capaz de informar seu destino. A bengala fornece informações posicionais via áudio ao usuário, por exemplo, o nome de uma rua ou estabelecimento, o bloco e o número da sala de aula no campus universitário, o nome de uma loja em um shopping, etc., incrementando o ambiente. Assim, a bengala conversa com o deficiente visual e indica o que está a sua volta, bem como os caminhos que deve seguir para chegar e sair de um determinado local (UTFPR, 2017, online).

\section{APRESENTAÇÃO E FUNDAMENTAÇÃO DA PROPOSTA}

\subsection{Metodologia da pesquisa}

A metodologia do trabalho subdivide-se em: a) visão de mundo e teoria base; b) método de abordagem; e c) procedimentos e técnicas.

A visão de mundo adotada é a sistêmica em cotejo com a teoria base de Humberto R. Maturana e Francisco J. Varela. O método de abordagem consiste no método indutivo, partindose do levantamento de premissas menores, denominadas de "perturbações" (situações jurídicas) que servirão de critérios de avaliação dos relatórios, alcançando premissas gerais. Os procedimentos empregados correspondem a pesquisas bibliográficas e estudo de caso (o Plano

público com eficiência e possui baixo custo. De acordo com a estimativa dos pesquisadores, o equipamento, formado por componentes vendidos comercialmente, custaria no mercado por volta de R \$200,00 (duzentos reais) (JORNAL DA UNICAMP, 2012, online). 
de Ação em IoT para o Brasil 2017-2022), e as técnicas para tanto integram a análise bibliográfica e a análise dos relatórios jurídicos.

Diante disso, considerando: a) a visão sistêmica baseada na noção de "autopoiese"; b) os exemplos práticos de interações entre Internet e o meio; c) as subáreas do Direito que irão interagir com a tecnologia; e d) o aparato legal vigente que representam essas subáreas (a Constituição Federal, o Código Civil, o Código de Defesa do Consumidor, o Código Tributário, entre outras leis), identificou-se, então, cinco fenômenos da realidade jurídica denominadas de "perturbações", conforme detalhado no Quadro 1.

Quadro 1: Identificação das perturbações/situações jurídicas relacionadas à implementação de IoT

\begin{tabular}{|c|c|c|}
\hline Perturbação & Subárea do Direito & Especificação \\
\hline 1 & $\begin{array}{l}\text { Direito Civil e do } \\
\text { Consumidor, Direitos } \\
\text { da Personalidade }\end{array}$ & $\begin{array}{l}\text { Conflitos como a violação da privacidade e da segurança a } \\
\text { partir de invasões e ataques hackers, além da coleta e } \\
\text { circulação comercial não autorizada de dados pessoais, } \\
\text { dado o grande volume de informações armazenado. }\end{array}$ \\
\hline 2 & $\begin{array}{l}\text { Direito Empresarial ou } \\
\quad \text { Concorrencial }\end{array}$ & 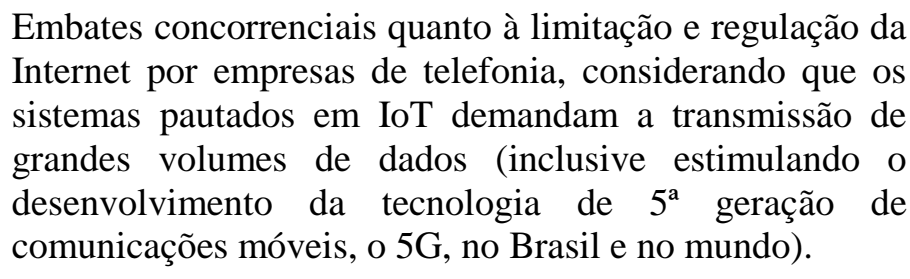 \\
\hline 3 & Direito Tributário & $\begin{array}{l}\text { Discussões acerca da tributação incidente, tendo em vista } \\
\text { que a grande maioria dessas tecnologias, ou mesmo seus } \\
\text { componentes, é originariamente estrangeira. }\end{array}$ \\
\hline 4 & $\begin{array}{c}\text { Direito Civil e do } \\
\text { Consumidor, } \\
\text { Responsabilidade Civil }\end{array}$ & $\begin{array}{l}\text { Uso inconsciente e inseguro da tecnologia, vindo a causar } \\
\text { danos ao usuário e/ou a terceiros. }\end{array}$ \\
\hline 5 & Sociologia Jurídica & $\begin{array}{l}\text { Desigualdade de oportunidades e benefícios em IoT } \\
\text { destinados a classes sociais apartadas. }\end{array}$ \\
\hline
\end{tabular}

FONTE: Desenvolvido pelos autores.

O caso que se propõe a estudar é o Plano de Ação em IoT para o Brasil 2017/2022, que foi composto de relatórios publicados nos sítios eletrônicos dos órgãos governamentais que lideraram a iniciativa (BNDES e MCTIC). As “perturbações” serão utilizadas como critérios de avaliação, verificando como as questões passíveis de aferição pelo Direito estão sendo abordadas no Plano de Ação e qual o seu maior enfoque jurídico. 


\subsection{Estudo de caso: avaliação qualitativa dos relatórios jurídicos apresentados no Plano de Ação em IoT para o Brasil 2017/2022}

A IoT é uma tecnologia recém-almejada no Brasil, cujo estudo para a sua futura implementação iniciou-se ao final de 2016, com a iniciativa conjunta do BNDES e do MCTIC, e convergiu, recentemente, na publicação do Plano de Ação para o Brasil 2017/2022, objeto de análise nesta pesquisa. $\mathrm{O}$ estudo reuniu agentes públicos e privados, especialistas, formadores de opinião, organizações, associações, universidades, entidades e empresas do setor privado, e contou, ainda com o consórcio entre o McKinsey Global Institute, o Centro de Pesquisa e Desenvolvimento em Telecomunicações $(\mathrm{CPqD})$ e o escritório de advocacia Pereira Neto Macedo (MCTIC, 2016, online).

A Figura 1 apresenta as quatro fases do estudo, nas quais foram produzidos relatórios específicos, posteriormente publicados perante os sítios eletrônicos do BNDES e do MCTIC.

Figura 1: Publicações do estudo (relatórios) por fase

\begin{tabular}{|c|c|c|c|c|}
\hline & Fase 1 & Fase 2 & Fase 3 & Fase 4 \\
\hline \multirow[t]{11}{*}{ Relatários: } & $\begin{array}{l}\text { 1- Relatório de } \\
\text { benchmark (PDF - 10,5 } \\
\text { MB) }\end{array}$ & $\begin{array}{l}48 \text { - Relatório de entrevistas e } \\
\text { pesquisas - Fase II (POF. } \\
5,0 \text { MB) }\end{array}$ & $\begin{array}{l}\text { 4C - Relatório de entrevistas } \\
\text { e pesquisas - fase III (PDF - } \\
4,8 \mathrm{MB} \text { ) }\end{array}$ & $\begin{array}{l}10 \text { - Desenho do modelo de } \\
\text { governanç̧a para o. PNIoT (PDF - } \\
3,3 \mathrm{MB} \text { ) }\end{array}$ \\
\hline & $\begin{array}{l}\text { 2A-Sumário Executivo } \\
\text { de Roadmap } \\
\text { tecnológico (PDF - } \\
2.0 \mathrm{MB} \text { ) }\end{array}$ & $\begin{array}{l}\text { 5A - Apresentaçào do resultado } \\
\text { de priorizaçào de verticais (PDF } \\
-4,3 \mathrm{MB} \text { ) }\end{array}$ & $\begin{array}{l}7 \mathrm{~A} \text { - Relatốtio de } \\
\text { aprofundamento das } \\
\text { verticais - Cidades (PDF- } \\
4,3 \mathrm{MB} \text { ) }\end{array}$ & $\begin{array}{l}11 \text { - Desenho de plataformas de } \\
\text { inovação e Centros de } \\
\text { Competência (PDF - } 12 \mathrm{MB} \text { ) }\end{array}$ \\
\hline & $\begin{array}{l}28 \text { - Relatório Roadmap } \\
\text { Tecnológico } \\
\text { completo (POF - } 9.2 \mathrm{MB} \text { ) }\end{array}$ & $\begin{array}{l}58 \text { - Relatório de seleçào de } \\
\text { horizontais e verticais. } \\
\text { Parcial (POF- } 5,0 \mathrm{MB})\end{array}$ & $\begin{array}{l}7 B \text { - Relatório de } \\
\text { aprofundamento das } \\
\text { verticais - Saúde (POF - }\end{array}$ & $\begin{array}{l}\text { 12- Modelo Conceitual } \\
\text { Observatório de loT (PDF - } 9,1 \\
\text { MB) }\end{array}$ \\
\hline & 3A-Aspiraçào do Brasil & $\begin{array}{l}\text { 6- Relatório de seleçăa de } \\
\text { horizontais e verticais - }\end{array}$ & $5,4 \mathrm{MB})$ & $\begin{array}{l}\text { 13- Cartilha de Cidades (PDF - } 13 \\
\text { MB) }\end{array}$ \\
\hline & $\begin{array}{l}\text { para lot (PDF - } 2,0 \mathrm{MB}) \\
38 \text {. } \\
\text { Ambientes para lot (PDF } \\
=4,6 \mathrm{MB} \text { ) }\end{array}$ & Final $(P D F-10,0 \mathrm{MB})$ & $\begin{array}{l}\text { TC-Relatório de } \\
\text { aprofundamento das } \\
\text { verticais-Rural (PDF- } \\
4,8 \mathrm{MB} \text { ) }\end{array}$ & $\begin{array}{l}14 \text { - Desenho da Estrutura de } \\
\text { monitoramento (PMO) (PDF- } \\
4,7 \mathrm{MB})\end{array}$ \\
\hline & $\begin{array}{l}\text { 3C-Análise de } \\
\text { Demanda (PDF- } 4,7 \mathrm{MB})\end{array}$ & & $\begin{array}{l}70 \text { - Relatório de } \\
\text { aprofundamento das } \\
\text { verticais - Indústria (PDF - } \\
5,0 \mathrm{MB} \text { ) }\end{array}$ & \\
\hline & 30-Análise de oferta & & & \\
\hline & $\begin{array}{l}\text { 3E-Análise da } \\
\text { Horizontal Ambiente }\end{array}$ & & Açà (PDF - 3,3 MB) & \\
\hline & & & $\begin{array}{l}\text { 8B - Plano de } A c^{a ̀ o} \text { - Capitulo } \\
\text { Regulatório (PDF - } 2,6 \mathrm{MB} \text { ) }\end{array}$ & \\
\hline & $\begin{array}{l}\text { 3F- Análise de } \\
\text { Horizontais (PDF - } \\
6.8 \mathrm{MB} \text { ) }\end{array}$ & & $\begin{array}{l}9 \mathrm{~A} \text {-Relatório final do } \\
\text { estudo (PDF- } 7,65 \mathrm{MB})\end{array}$ & \\
\hline & $\begin{array}{l}\text { 4A-Relatório de } \\
\text { entrevistas e } \\
\text { pesquisas (ZIP 3,1 MB) }\end{array}$ & & $\begin{array}{l}98 \text { - Sintese do relatório final } \\
\text { do estudo (PDF - } 6,4, M B)\end{array}$ & \\
\hline
\end{tabular}

FONTE: BNDES (online). 
Visando organizar as metas dentro do Plano, foram estruturadas diversas iniciativas, organizadas em quatro horizontais, apontadas na Figura 3, quais sejam: 1. "Capital Humano"; 2. "Inovação e Inserção Internacional"; 3. "Regulatório, Segurança e Privacidade" e 4. "Infraestrutura de Conectividade e Interoperabilidade". Como decorrência, foi definida uma série de objetivos específicos para cada horizontal traçada, a serem alcançados no decorrer do estudo, com a produção dos relatórios.

Priorizou-se, na pesquisa, a horizontal "Regulatório, Segurança e Privacidade", em razão de sua natureza jurídica, e cujos objetivos específicos ali definidos são passíveis de manifestação pelo Direito.

Figura 2: Principais temas de IoT transversais a todos os ambientes - as horizontais

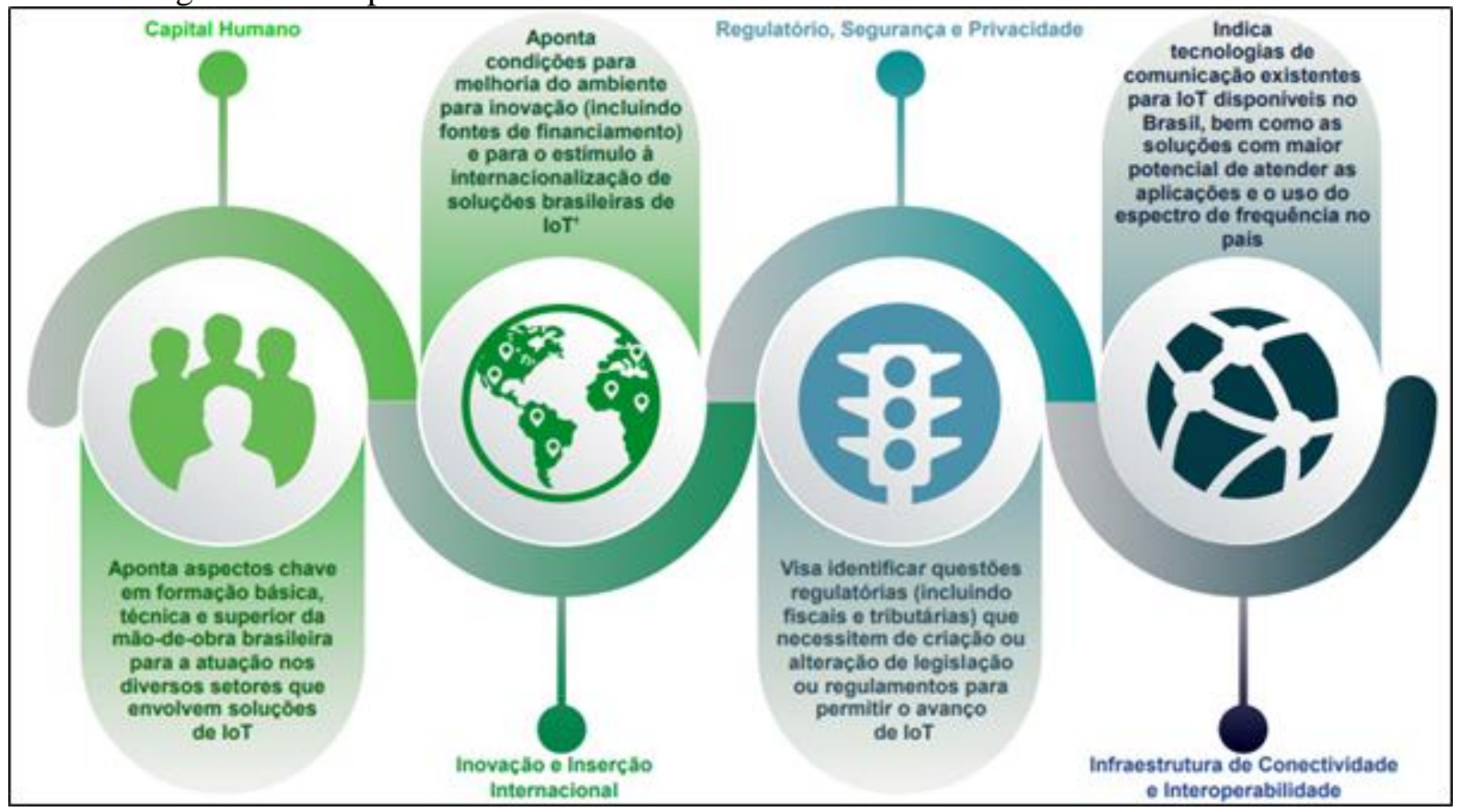

FONTE: Produto 9B - Síntese do Relatório Final do Estudo, BNDES (2018b, online).

Realizada a avaliação dos relatórios, o Quadro 2 demonstra os níveis de abordagem de cada perturbação levantada no Quadro 1, sendo "P3" como perturbação/situação jurídica amplamente abordada; "P2" como perturbação/situação jurídica parcialmente abordada; "P1" como perturbação/situação jurídica pouco abordada e "P0" como situação jurídica não abordada.

Quadro 2: Avaliação do nível de abordagem das perturbações/situações jurídicas identificadas 


\begin{tabular}{|c|c|c|}
\hline Perturbação & Relatório e localizaçãa & $\begin{array}{l}\text { Nível de } \\
\text { abordagem }\end{array}$ \\
\hline 1 & $\begin{array}{l}\text { 3E - Análise da Horizontal Ambiente Regulatório, itens } \\
\text { 3.3 e } 3.4 \\
\text { 8B - Plano de Ação - Capítulo Regulatório, itens } 2.2 \text { e } 2.3 \\
\text { 9A - Relatório Final do Estudo, item 5.3.4 }\end{array}$ & P3 \\
\hline 2 & $\begin{array}{l}\text { 3E - Análise da Horizontal Ambiente Regulatório, item } \\
3.1 \\
\text { 8B - Plano de Ação - Capítulo Regulatório, item 2.1 } \\
\text { 9A - Relatório Final do Estudo, item 5.3.4 }\end{array}$ & P3 \\
\hline 3 & $\begin{array}{l}\text { 3E - Análise da Horizontal Ambiente Regulatório, itens } \\
\text { 3.5, 3.6 e } 3.7\end{array}$ & $\mathrm{P} 2$ \\
\hline 4 & Não localizado & $\mathrm{P} 0$ \\
\hline 5 & 3F - Análise de Horizontais, item 4 & $\mathrm{P} 1$ \\
\hline
\end{tabular}

FONTE: Desenvolvido pelos autores.

\subsection{Análise e discussão dos resultados}

3.3.1 Direito Civil e do Consumidor, Direitos da Personalidade: privacidade e segurança de dados

O tema privacidade e segurança de dados foi amplamente abordado (P3).

Os relatórios apresentaram os principais normativos vigentes que são aplicáveis ao tema em geral, como: a) a Constituição Federal $^{2}$, no que se refere à inviolabilidade da intimidade e da vida privada, ao sigilo de comunicações e ao instrumento do habeas data; b) o Código de Defesa do Consumidor ${ }^{3}$, no que se refere à responsabilidade objetiva pela violação à segurança dos serviços ou da base de dados, à obtenção de consentimento do consumidor na coleta e no tratamento de dados, à boa-fé objetiva quanto à expectativa do consumidor, e ao direito de acesso por titulares às informações armazenadas em bases de dados; c) o Código Civil ${ }^{4}$, no que se refere ao direito à integridade psicofísica, ao nome e ao pseudônimo, à imagem e à inviolabilidade da vida privada, sua intransmissibilidade e irrenunciabilidade; d) a Lei de Acesso à Informação ${ }^{5}$ no que se refere à transparência e à obrigação dos órgãos públicos de fornecer informações pessoais independente de solicitação do cidadão ou após demanda por ele

\footnotetext{
${ }^{2}$ Art. $5^{\circ}$, X, XII e LXXII.

${ }^{3}$ Arts. $4^{\circ}$, III; $6^{\circ}$, III; $42, \S 2^{\circ}$; e $43, \S \S 1^{\circ}$ e $3^{\circ}$.

${ }^{4}$ Arts. 11 a 21 .

${ }^{5}$ Art. 31.
} 
apresentada; e) o Marco Civil da Internet $^{6}$, que enfatiza o consentimento do usuário ao estabelecer princípios quanto ao tratamento de dados pessoais, como a justificação da coleta, a não vedação pela legislação e a especificação contratual, e ainda prevê obrigações relativas à guarda de registros e dados pessoais, cuja violação incorre em responsabilizações; e f) o Decreto n. 8.771/2016 ${ }^{7}$ que regulamenta o MCI e traz definições atuais de dado pessoal e de tratamento de dados pessoais (BNDES, 2017a, p. 35-50).

Os relatórios também apontaram para o fato de que essa fragmentação legislativa acaba por gerar uma insegurança jurídica em decorrência das interpretações distintas que eventualmente refletirá no ambiente da IoT, ressaltando a urgência de uma legislação única sobre o tema, cujo projeto estava em trâmite de aprovação na época (BNDES, 2017a, p. 50-51). Nessa perspectiva, indicaram-se alguns pontos que necessitam ser abarcados na legislação como a criação ou designação de uma autoridade de proteção de dados pessoais (BNDES, 2017a, p. 51-52; 2018a, p. 79-82).

A existência de uma autoridade sobre o tema foi algo realçado no estudo, uma vez que ela decorreu dos consensos obtidos durante o processo de formulação e consultas públicas. Foram analisadas as experiências institucionais da União Europeia e dos Estados Unidos, a autoridade constituída no Uruguai e as propostas normativas sobre o tema atualmente em trâmite no Congresso Nacional. Dentre as principais justificativas voltadas à formação dessa instância regulatória está o fato de que a observância de normas relativas à privacidade atualmente são objeto de fiscalização e atuação de múltiplas entidades consecutivamente: SENACON (ligada ao Ministério da Justiça), Ministério Público Federal, Ministério Público Estadual etc. e o fato de que o tema demanda um controle unificado e homogêneo no âmbito mercadológico. $\mathrm{O}$ estudo propôs que essa autoridade central seja instituída dentro de um modelo de co-regulação (compartilhamento de responsabilidades regulatórias entre governo e agentes privados), com incentivo de práticas transitórias de auto-regulação (responsabilidade regulatória conduzida pelos agentes privados) (BNDES, 2017c, p. 25-43).

Quanto à segurança da informação, a maior problemática identificada residiu nos crescentes riscos sistêmicos trazidos por IoT, como aqueles decorrentes de falhas na implementação de protocolos de segurança (dispositivos mantidos com senhas padrões ou até mesmo sem a possibilidade de alteração de senha) e os riscos derivados de vulnerabilidades. Esses riscos se tornam ainda mais latentes diante da utilização de aplicações IoT em

\footnotetext{
${ }^{6}$ Arts. $7^{\circ}$, VIII a X; 10 a 17.

${ }^{7}$ Arts. 13 e 14 .
} 
infraestruturas críticas, tendo em conta o potencial lesivo de ataques em redes de prestação de água e energia, por exemplo. Nesse sentido, foram discutidos modelos de governança tanto para a cooperação internacional, quanto em relação ao arranjo institucional interno brasileiro diante da natureza "sem fronteiras" de incidentes em segurança da informação e da expansão de vulnerabilidades em redes com o desenvolvimento da IoT, com a análise de convenções e de organizações internacionais, além do incentivo à adoção de critérios mais rigorosos na certificação, incluindo a possibilidade de utilização da tecnologia blockchain para tanto, recurso promissor na prevenção de fraudes (BNDES, 2017a, p. 52-53; 2017c, p. 44-64; 2018a, p. 2829).

\subsubsection{Direito Empresarial e Concorrencial: limitação e regulação da Internet}

O tema relativo às limitação e regulação da Internet (telecomunicações em geral) também foi amplamente abordado (P3).

A preocupação inicial do assunto se deu quanto ao acesso à Internet no Brasil, considerando que segundo a ANATEL, atualmente mais de cinco mil municípios brasileiros contam com cobertura de Internet, o que não significa, entretanto, que a cobertura é sinônimo de acesso ou de acesso com qualidade para efeitos da utilização de aplicações de IoT.

Sendo assim, foram identificadas duas situações que demandam tratamentos distintos: a) localidades sem acesso às redes de telecomunicações; e b) potenciais usuários que, embora tecnicamente estejam em áreas atendidas, não dispõem de recursos para contratar os serviços. Nesse aspecto, o Projeto de Lei n. 79/2016 aborda a possibilidade de migração do regime de concessão para autorização na prestação de serviços de telecomunicações, o que amplia o acesso, e o Projeto de Lei n. 7.406/2014 propõe alterações das regras do Fundo de Universalização dos Serviços de Telecomunicações (o "FUST", instituído pela Lei n. 9.998/2000) para que seus recursos sejam aplicados na massificação da banda larga (BNDES, 2017a, p. 8-10; 2017c, p. 8-9).

Outro ponto de abordagem consistiu na necessidade de obtenção, pelo ofertante de IoT, de prévia autorização para a prestação de serviço de telecomunicações junto à ANATEL. Foram delimitadas as divergências em torno da prestação de serviço de telecomunicações que demanda outorgas do Serviço de Comunicação Multimídia (“SCM”), do Serviço Móvel Pessoal (“SMP”) ou do Serviço Limitado Privado (“SLP”), e, ainda, a prestação por meio do Serviço de Valor Adicionado ("SVA") que dispensa essa outorga. Também foi debatido a respeito do roaming 
internacional permanente, que se trata do oferecimento de aplicações de IoT que estejam conectadas a serviço de telecomunicações provido por empresa não prestadora no País e o risco de caracterização de prestação irregular. Além disso, foi abordado o uso do espectro de radiofrequência, incluindo o espectro licenciado, que depende de autorização da ANATEL para utilização, e o espectro não licenciado, que independe dessa autorização, como ocorre com o Wi-Fi (BNDES, 2017a, p. 8-24; 2017c, p. 10-18; 2018a, p. 79).

Diante dessas questões, o estudo inicia a discussão sobre a instituição (ou não) de tratamento diferenciado para o ambiente dos serviços que envolvam IoT, verificando-se a possibilidade de redução de custos relacionados às taxas de fiscalização (como a do Fundo de Fiscalização das Telecomunicações - "FISTEL"), no intuito de promover uma assimetria regulatória de forma efetiva para as aplicações de IoT. Um exemplo de desoneração, segundo o art. 38, da Lei n. 12.715/2012, é para equipamentos que se classificam como sendo de comunicação machine-to-machine ou máquina a máquina (“M2M”), cuja definição é trazida, de forma ampla, pelo art. $1^{\circ}$, do Decreto n. 8.234/2014, como "dispositivos que, sem intervenção humana, utilizem redes de telecomunicações para transmitir dados a aplicações remotas $[\ldots]$ ”. . No entanto, essa definição é passível de dúvidas sobre o que, exatamente, seria considerado ausência de intervenção humana em uma determinada comunicação. Outra discussão que se relaciona ao assunto é a atual impossibilidade de conceder um tratamento diferenciado em função da aplicação que será suportada pelo serviço de telecomunicações, em especial naqueles de interesse coletivo que podem servir de suporte para aplicações de IoT. Nesse sentido, a assimetria regulatória no âmbito da IoT é algo a ser refletido, pois várias dessas aplicações possuem um contato mínimo humano, sem deixarem, porém, de ser afetas ao ecossistema IoT, e que acabariam não se beneficiando do tratamento assimétrico, em razão da inconsistência do critério "sem intervenção humana" previsto pelo art. $1^{\circ}$, do Decreto n. 8.234/2014 (BNDES, 2017a, p. 28-32).

Ante esse quadro, e amparado pelas contribuições recebidas na ocasião da consulta pública, o estudo insistiu na necessária redefinição do conceito de machine-to-machine (“M2M") ou comunicação máquina a máquina presente no Decreto n. 8.234/2014. Para tanto, recorrendo-se à experiência legislativa estrangeira (no caso, da Alemanha, apontada nos relatórios), os elaboradores trouxerem expressões jurídicas indeterminadas e que podem conduzir para uma maior flexibilidade do conceito, compreendendo a comunicação M2M como aquela "predominantemente automatizada" ou sem a necessidade de intervenção humana “direta e consciente”, o que poderá favorecer as aplicações de IoT (BNDES, 2017c, p. 6-8). 
Em que pese a ampla abordagem sobre o assunto, entende-se que o estudo poderia ter reportado, ainda que a nível de aspiração, o assunto a respeito da tecnologia de $5^{\text {a }}$ geração de comunicações móveis, o 5G, por ser um instrumento promissor voltado à efetivação das aplicações de IoT no Brasil, e tendo em vista a parceria realizada entre o MCTIC, a Telebrás e a 5G Infraestrucuture Association (5GIA), uma organização que reúne empresas e desenvolvedores da tecnologia na União Europeia. A propósito, segundo a 5GIA, o Brasil é um dos quatro países estratégicos para a colaboração conjunta no desenvolvimento da tecnologia, ao lado da China, Japão e Coreia do Sul (GOVERNO DO BRASIL, 2017, online).

\subsubsection{Direito Tributário: tributação incidente}

O tema relativo à tributação foi parcialmente abordado (P2).

Como exposto no estudo, o Sistema Tributário Nacional apresenta desafios no que tange ao desenvolvimento da IoT no Brasil, por haver sobreposição de atividades que envolvem desde a importação de componentes, venda interna de dispositivos, utilização de serviços de telecomunicação, realização do Serviço de Valor Adicionado ("SVA”) e serviços de outra natureza (como licenciamentos e desenvolvimento de software). Diante da natureza híbrida da IoT, questões relevantes podem surgir, pelos seguintes motivos: a) há um acúmulo de tributos sobre consumo que geram cargas fiscais efetivas bastante elevadas, sofrendo a incidência múltipla de tributos sobre consumo, os quais, inclusive, incidem de maneira cumulativa; b) há inúmeras incertezas quanto à competência para tributar determinados serviços, diante da falta de clareza do que sejam os serviços de comunicação (sujeito ao Imposto sobre Operações relativas à Circulação de Mercadorias e Prestação de Serviços de Transporte Interestadual e Intermunicipal e de Comunicação - o "ICMS", imposto estadual) e do que estaria fora desse conceito (sujeito ao Imposto sobre Serviços de Qualquer Natureza - o "ISS", imposto municipal); e b) há complexidade para aprovar qualquer mudança no sistema, de forma que o atual sistema tributário ainda encontra-se sob os contornos dados pela Constituição Federal de 1988 e ancorado em um Código Tributário Nacional de 1966 (BNDES, 2017a, p. 53-54).

Dado esse contexto, visualizou-se no relatório a preocupação em discorrer sobre os possíveis questionamentos advindos da relação da IoT com o Imposto sobre a Renda ("IR"), com o Imposto sobre Circulação de Mercadorias e Serviços (“ICMS”) e com o Imposto sobre Serviços de Qualquer Natureza (“ISS"), isto é, questionamentos em torno da venda e da aquisição de bens para consumo e os lucros decorrentes (BNDES, 2017a, p. 53-57). E, no 
sentido de facilitação do desenvolvimento de IoT, também constatou-se a preocupação em ressaltar alguns benefícios fiscais já existentes, como o Lucro da Exploração, instituído pela Medida Provisória n. 2.199-14/2001; os benefícios previstos na Lei n. 11.196/2005, que institui o Regime Especial de Tributação para a Plataforma de Exportação de Serviços de Tecnologia da Informação - Repes; os benefícios provenientes da Zona Franca de Manaus, regulada pelo Decreto-Lei n. 288/1967; e ainda, os benefícios acerca do Imposto sobre Produtos Industrializados - "IPI”, dispostos na Lei n. 8.248/1991 (conhecida como "Lei da Informática”). Por fim, o estudo discorreu brevemente sobre o processo de importação e desembaraço aduaneiro no Brasil, o que impactará no desenvolvimento e na expansão de soluções de IoT (BNDES, 2017a, p. 55-64).

Todavia, percebe-se que o estudo não se propôs a examinar, em específico, o Imposto de Importação - "II" e o Imposto de Exportação - "IE", dada a sua natureza extrafiscal, o que possibilita a intervenção do Estado na economia no sentido de incentivo/desincentivo da produção industrial nacional. Nesse ponto, entende-se que a chegada da IoT no Brasil poderá ser uma forma de alcançar o diálogo entre o ente público e o privado, gerando benefícios fiscais diretos e indiretos aos operadores e usuários da tecnologia, além do estímulo ao seu desenvolvimento, situação que poderia ter sido melhor examinada no estudo, dado o seu caráter propositivo. Outra questão que careceu de maior análise foi a necessidade iminente de reforma do Sistema Tributário Nacional, em especial no tocante à tributação sobre o consumo, que é a mais deturpada atualmente e demanda simplificação. Nesse ponto, os relatórios finais do estudo poderiam ter oferecido caminhos para se reduzir essa complexidade (como por exemplo, via incidência de uma tributação unificada), tendo em conta que a IoT potencializará os conflitos fiscais em torno do assunto.

3.3.4 Direito Civil e do Consumidor, Responsabilidade Civil: danos aos usuários e a terceiros

O tema relativo à responsabilização por danos advindos do uso inseguro e inconsciente não foi abordado nos relatórios (P0), limitando-se a invocar, na parte relativa à privacidade, a responsabilidade objetiva disciplinada pelo Código de Defesa do Consumidor com relação aos usuários que forem acometidos por danos decorrentes do tratamento indevido de dados pessoais.

\subsubsection{Sociologia Jurídica: oportunidades em IoT}

Rev. de Direito, Governança e Novas Tecnologias | e-ISSN: 2526-0049 | Goiânia| v. 5 | n. 1 | p. 1-22| Jan/Jun. 2019 
$\mathrm{O}$ tema relativo às oportunidades sociais foi pouco abordado nos relatórios (P1) e não foi objeto de estudo nos relatórios acerca da horizontal "Regulatório, Segurança e Privacidade".

Localizou-se, apenas, uma preocupação voltada em identificar os principais desafios em capital humano que precisam ser enfrentados para apoiar o crescimento da IoT no país. Esses desafios foram delineados em: a) educação básica, ocasião em que foram apontadas questões como a falta de alinhamento entre a formação de jovens e as necessidades do mercado de trabalho, a adaptação da estrutura curricular, a dificuldade de acesso ao ensino de superior, a incerteza sobre o valor da educação superior e o viés social contra algumas profissões técnicas; b) educação para o trabalho, sobretudo em relação à falta de habilidades como principal razão para o não preenchimento de vagas de emprego; e b) atração e desenvolvimento de capital humano, o que depende da formação superior de cientistas e de investimento em pesquisa básica e aplicada, ambos pontos fracos do Brasil (BNDES, 2017b, p. 19-26).

Nesse aspecto, o relatório indicou que o baixo investimento em pesquisa nas áreas de engenharia e tecnologia é refletido no número de publicações científicas, ilustrando que segundo dados do Scimago Journal \& Country Rank, em 2015 houve cerca de 1.600 publicações científicas com citações no Brasil na área de Engenharia e outras 600 na área de Ciência da Computação, ao passo que na China esse número foi de 36,4 mil e 9,7 mil, respectivamente. Além disso, o baixo investimento também se reflete na pós-graduação, pois, segundo dados do CNPq, de um total de 163 mil bolsas concedidas em 2015, apenas 26 mil foram nas áreas de engenharia e tecnologia (BNDES, 2017b, p. 27-28).

\subsection{Matérias jurídicas a serem abordadas em estudos futuros}

A primeira matéria corresponde às subáreas de Direito Civil e do Consumidor, Responsabilidade Civil, em especial aos conflitos decorrentes de danos ocasionados a consumidores/usuários e a terceiros pela tecnologia.

Quando se trata de produtos e serviços alavancados com IoT, o uso inconsciente e inseguro por seus destinatários é um tema que requer diligência, uma vez que ele atravessa diversos regimes de responsabilidade civil no âmbito da legislação e doutrina brasileiras, entre eles: a) a responsabilidade civil subjetiva regida pelo Código Civil (regra geral, a ser acionada em relações business to business - $\mathrm{B} 2 \mathrm{~B}$ ); b) a responsabilidade civil objetiva regida pelo Código de Defesa do Consumidor (regra específica, a ser acionada em relações business to consumer-

Rev. de Direito, Governança e Novas Tecnologias | e-ISSN: 2526-0049 | Goiânia| v. 5 | n. 1 | p. 1-22| Jan/Jun. 2019 
"B2C", especialmente em caso de vício e fato do produto e vício e fato do serviço, sendo este último denominado pela doutrina também por “acidente de consumo", além da responsabilidade do profissional liberal); c) a responsabilidade objetiva ou subjetiva do Estado regida pela Constituição Federal (regra específica, a ser acionada em relações government to consumer “G2C", especialmente em atos comissivos e omissivos da Administração Pública voltados ao serviço público); e d) a responsabilidade subjetiva dos provedores de Internet regida pelo Marco Civil da Internet (regra específica, a ser acionada em qualquer relação na qual esteja presente a figura do provedor, especialmente em atos omissivos diante de conteúdos gerados por terceiros).

Nesse ponto, não se descarta a elaboração de legislações que esclareçam o(s) regime(s) de responsabilidade civil incidente(s) em caso de danos decorrentes de aplicações de IoT, ou estabelecendo um regime especial (como ocorreu com o caso dos provedores), no intuito de sanar dúvidas diante da aplicabilidade dos binômios "objetiva e subjetiva", "atos comissivos e atos omissivos", partindo-se do pressuposto de que, em se tratando de aplicações de IoT, estarse-á diante de formas de responsabilidade civil tanto contratual como extracontratual.

A segunda matéria, por sua vez, refere-se à subárea de Sociologia Jurídica, com destaque à eventual desigualdade de oportunidades em IoT destinadas a classes sociais apartadas, além do tema relativo à inclusão social com relação aos benefícios trazidos pela tecnologia.

Diferentemente do que foi abordado nos relatórios, compreende-se a inclusão social e o gerenciamento de oportunidades são perturbações que ultrapassam os problemas relativos à educação básica e superior no País. De que certo que a implementação de IoT no Brasil abrirá inúmeras portas, desde o segmento profissional ou acadêmico, como também no sentido de melhora da qualidade dos serviços e produtos incrementados com a tecnologia.

Contudo, a concretização e distribuição dessas oportunidades requer a efetiva participação da sociedade em todos os passos - incluindo a elaboração do Plano de Ação até a chegada da IoT - seja indicando o que se espera com a tecnologia, suas vantagens e desvantagens, ou ainda, seja auxiliando na própria construção de canais institucionais aptos para que as pessoas possam se manifestar, se expressar, isto é, fazer parte do processo de tomada das decisões relativas ao assunto.

Um exemplo de que a inclusão e a participação social podem ser materializadas com a implementação da IoT foi verificado no projeto "bengala inteligente", da UTFPF, referido na seção 2.2, no qual um dos alunos integrantes possui deficiência visual, o que auxiliou de forma 
significativa na elaboração e na experimentação do produto, eliminando, diretamente, as dúvidas surgidas no decorrer do projeto (YOUTUBE, 2017, online).

Enfim, são inúmeros os avanços e as contribuições da IoT quando combinada com as diversas interfaces. Essas novas ferramentas devem ser viabilizadas ao público interessado, cujos benefícios devem ser usufruídos pela comunidade em geral e gerações futuras, sem qualquer tipo de exclusão. Para tanto, regulamentações e orientações serão necessárias, mas também deverão ser acertadas, evitando a criação de barreiras onde o fomento é possível (SABO; SABO; TEIXEIRA; ROVER, 2017, p. 19).

\section{CONCLUSÃO}

Conforme apresentado, são inúmeras e relevantes as vantagens que a inserção da IoT no Brasil poderá trazer à população, em diversos setores, como o urbanístico, o econômico, o ambiental, além de propiciar inovação, empreendedorismo e, sobretudo, inclusão social. Para que essas vantagens estejam ao alcance de toda a sociedade e que os conflitos sejam reduzidos, a atuação do Direito deverá intermediar o incentivo ao desenvolvimento da tecnologia e o resguardo quanto às possibilidades de riscos e danos aos seus destinatários.

Visualizar o tema a partir do fenômeno da autopoiese de Humberto R. Maturana e Francisco J. Varela, permitiu compreender o aspecto sistêmico da tecnologia, cujos interesses despertados ultrapassam diversas áreas do conhecimento, incluindo o Direito, ao qual caberá dirimir as perturbações do meio que refletem no mundo jurídico, em prol do desenvolvimento das aplicações de IoT. E, nesse âmbito, é possível que Direito se manifeste de diversas maneiras em face do tema proposto, seja por intermédio das normas vigentes analisadas, ou elaborações de normas futuras, pois, como visto, o tema em debate abre espaço para novos questionamentos jurídicos não respondidos pela legislação atual.

Nesse propósito, as "perturbações" do meio, identificadas como situações jurídicas presentes nas subáreas do Direito, possuem a capacidade de modificar a estrutura da tecnologia de modo positivo, ocasião em que norma servirá para aperfeiçoar o seu uso pela sociedade, além de abrir outros campos de interação. No entanto, essas mesmas perturbações, uma vez não observadas, poderão afastar e extinguir o uso dessa mesma tecnologia, modificando a sua estrutura de forma negativa e, consequentemente, destruindo a sua organização, momento em que estar-se-á diante de uma norma em desuso. 
É preciso salientar que o estudo proposto pelo BNDES em parceria com o MCTIC não deixa de ser uma iniciativa notável, contendo diversas problemáticas jurídicas acompanhadas de análise doutrinária e legislativa, além de representar um significativo avanço na implementação da IoT no Brasil, sendo capaz de situar o País junto às principais potências tecnológicas do cenário mundial.

Os resultados apontaram que o enfoque jurídico do Plano de Ação não segue a ótica sistêmica, uma vez que a prioridade do estudo se voltou a delinear as principais limitações jurídicas e incentivos legais que interessam somente ao empresariado, dando-se pouca importância à expectativa por parte da sociedade em geral, destinatária dos produtos e serviços incrementados pela IoT.

Espera-se, portanto, que a pesquisa exposta contribua no sentido crítico para que os órgãos públicos e o setor privado, nos próximos estudos, reservem maior espaço e atenção para a inclusão social em prol da visão mercadológica, pois, para que se alcance uma sociedade integralmente conectada, é necessário promover meios para ouvir todos os beneficiados pela nova tecnologia, obtendo-se a participação de todos os envolvidos nos debates acerca do tema IoT.

\section{REFERÊNCIAS}

AUDI USA. Audi announces the first vehicle to infrastructure (V2I) service: the new Traffic light information system, 15 aug. 2016. Disponível em: $<$ https://www.audiusa.com/newsroom/news/press-releases/2016/08/audi-announces-firstvehicle-to-infrastructure-service>. Acesso em: 05 nov. 2016.

BIGBELLY. Disponível em: <http://bigbelly.com>. Acesso em: 05 nov. 2016.

BNDES. Estudo "Internet das Coisas: um Plano de Ação para o Brasil". Disponível em: $<$ https://www.bndes.gov.br/wps/portal/site/home/conhecimento/pesquisaedados/estudos/estud o-internet-das-coisas-iot/estudo-internet-das-coisas-um-plano-de-acao-para-o-brasil> . Acesso em: 19 abr. 2018.

BNDES. Internet das Coisas: um Plano de Ação para o Brasil (Produto 3E - Análise da Horizontal Ambiente Regulatório), 2017a. Disponível em:

$<$ https://www.bndes.gov.br/wps/wcm/connect/site/e614e9a3-053b-42d4-853a6b4aa406e31f/produto-3-analise-de-oferta-e-demanda-relatorio-horizontal-ambienteregulatorio.pdf?MOD=AJPERES\&CVID=lWrmVIj>. Acesso em: 4 jun. 2018.

BNDES. Internet das Coisas: um Plano de Ação para o Brasil (Produto 3F - Análise de Horizontais), 2017b. Disponível em:

$<$ https://www.bndes.gov.br/wps/wcm/connect/site/e0620a72-9e24-480a-a6cf- 
d6c29597c654/produto-3-analise-de-oferta-e-demanda-relatorio-

horizontais.pdf?MOD=AJPERES\&CVID=m0jFBGA>. Acesso em: 5 jun. 2018.

BNDES. Internet das Coisas: um Plano de Ação para o Brasil (Produto 8B - Plano de Ação Capítulo Regulatório), 2017c. Disponível em:

<https://www.bndes.gov.br/wps/wcm/connect/site/f9582d36-4355-4638-b931-

e2e53af5e456/8B-relatorio-final-plano-de-acao-produto-ambiente-

regulatorio.pdf?MOD=AJPERES\&CVID=m7tyLs1>. Acesso em: 4 jun. 2018.

BNDES. Internet das Coisas: um Plano de Ação para o Brasil (Produto 9A - Relatório Final do Estudo), jan. 2018a. Disponível em:

$<$ https://www.bndes.gov.br/wps/wcm/connect/site/d22e7598-55f5-4ed5-b9e5-

543d1e5c6dec/produto-9A-relatorio-final-estudo-de-

iot.pdf?MOD=AJPERES\&CVID=m5WVIld>. Acesso em: 5 jun. 2018.

BNDES. Internet das Coisas: um Plano de Ação para o Brasil (Produto 9B - Síntese do

Relatório Final do Estudo), jan. 2018b. Disponível em:

<https://www.bndes.gov.br/wps/wcm/connect/site/445c4dd8-069b-47c1-b191-

767caee4a5ae/produto-9B-relatorio-final-sintese-do-estudo-de-Iot-

atualizado.pdf?MOD=AJPERES\&CVID=m87qOtl>. Acesso em: 5 jun. 2018.

CASTRO, Daniel; MISRA, Jordan. The internet of things. Center for Data Innovation, nov. 2013, p. 14 e 18. Disponível em: <http://www2.datainnovation.org/2013-internet-ofthings.pdf >. Acesso em: 13 mar. 2017.

FLEISCH, Elgar. What is the Internet of Things? An economic perspective. Auto-ID Labs White Paper, jan. 2010.

HIKOB. Disponível em: <http://www.hikob.com/en>. Acesso em: 05 nov. 2016.

JORNAL DA UNICAMP. Tecnologia mede grau de conforto oferecido pelo transporte coletivo. Campinas, a. XXVI, n. 521, mar./abr. 2012. Disponível em:

$<$ http://www.unicamp.br/unicamp/ju/521/tecnologia-mede-grau-de-conforto-oferecido-pelotransporte-coletivo>. Acesso em: 29 mar. 2017.

MATURANA, Humberto R.; MAGRO, Cristina; GRACIANO, Miriam; VAZ, Nelson. A ontologia da realidade. Belo Horizonte: UFMG, 1997.

MATURANA, Humberto R.; MAGRO, Cristina; PAREDES, Victor. Cognição, ciência e vida cotidiana. Belo Horizonte: UFMG, 2001.

MATURANA, Humberto R.; VARELA, Francisco J. Tradução de Humberto Mariotti e Lia Diskin. A árvore do conhecimento: as bases biológicas da compreensão humana. 8. ed. São Paulo: Palas Athena, 2010.

MATURANA, Humberto R.; VARELA, Francisco J. De máquinas e seres vivos: autopoiese - a organização do vivo. 3. ed. Tradução de Juan Acuña Llorens. Porto Alegre: Artes

Médicas, 1997. 
MCTIC, Ministério da Ciência, Tecnologia, Inovações e Comunicações. MCTIC e BNDES formalizam nesta segunda-feira parceria estratégica em Internet das Coisas, $09 \mathrm{dez}$. 2016. Disponível em: <http://www.mcti.gov.br/noticia//asset_publisher/epbV0pr6eIS0/content/mctic-e-bndes-formalizam-nesta-segunda-feiraparceria-estrategica-em-internet-das-coisas>. Acesso em: 10 mar. 2017.

METRO. MetroBus. Disponível em: <http://www.metrostlouis.org/metrobus>. Acesso em: 05 nov. 2016.

GOVERNO DO BRASIL. Parceria entre Brasil e União Europeia vai desenvolver Internet das Coisas e 5G, 01 mar. 2017. Disponível em: <http://www.brasil.gov.br/ciencia-etecnologia/2017/03/parceria-entre-brasil-e-uniao-europeia-vai-desenvolver-internet-dascoisas-e-5g>. Acesso em: 22 mar. 2017.

SABO, Isabela Cristina; SABO, Paulo Henrique; TEIXEIRA, Tarcisio; ROVER, Aires José. Internet das Coisas (IOT), ambientes e cidades inteligentes: expectativas da sociedade e do Direito. Revista Democracia Digital e Governo Eletrônico, Florianópolis, v. 1, n. 16, p. 1429, 2017.

SMART PALM. Disponível em: <http://smart-palm.com>. Acesso em: 05 nov. 2016.

SPENSA. Meet the Z-Trap. Disponível em: <http://spensatech.com/z-trap.html>. Acesso em: 05 nov. 2016.

UTFPR, Universidade Tecnológica Federal do Paraná. Deficiência visual, 13 fev. 2017. Disponível em: <http://www.utfpr.edu.br/campomourao/estruturauniversitaria/assessorias/ascom/noticias/ultimas-noticias-1/deficiencia-visual > . Acesso em: 20 fev. 2017.

WATERBEE. Disponível em: <http://waterbee-da.iris.cat>. Acesso em: 05 nov. 2016.

YOUTUBE. Alunos da UTFPR desenvolvem aparelho para cego, 08 fev. 2017. Disponível em: 〈https://www.youtube.com/watch?v=sFoMQbB9dnQ>. Acesso em: 20 fev. 2017. 